\title{
Racial and Ethnic Differences in Direct-to-Consumer Genetic Tests Awareness in HINTS 2007: Sociodemographic and Numeracy Correlates
}

\author{
Aisha T. Langford $\cdot$ Ken Resnicow $\cdot$ J. Scott Roberts • \\ Brian J. Zikmund-Fisher
}

Received: 2 August 2011 /Accepted: 21 December 2011 /Published online: 21 January 2012

(C) National Society of Genetic Counselors, Inc. 2012

\begin{abstract}
To examine the association of 1) race/ethnicity and 2) numeracy with awareness of DTC genetic tests. Secondary analysis of 6,754 Hispanic, black, and white adult respondents to the National Cancer Institute's 2007 Health Information National Trends Survey (HINTS). Logistic regression was used to examine sociodemographic predictors of DTC genetic tests awareness including race/ ethnicity, income, education, and gender. Next, two numeracy variables were added to the model. After controlling for sociodemographic variables, black respondents were significantly less likely to have heard of DTC genetic tests compared to white respondents $(\mathrm{OR}=0.79$; $\mathrm{CI}$ : $0.65-0.97)$. When numeracy variables were added to the model, the effect of black race was no longer significant $(\mathrm{OR}=0.84$; CI: 0.69-1.04). Hispanic respondents did not significantly differ from white respondents in awareness of DTC genetic tests. Other significant correlates of DTC genetic tests awareness in the full model included education, income, age, and numeracy variables including degree to which people use medical statistics and numbers to make health decisions, and preference for words or numbers when discussing "the chance of something happening." Although black respondents were generally less aware of DTC genetic tests than white respondents, this relationship appears to be partially mediated by numeracy.
\end{abstract}

\footnotetext{
A. T. Langford $(\bowtie) \cdot$ K. Resnicow $\cdot$ J. S. Roberts $\cdot$

B. J. Zikmund-Fisher

Department of Health Behavior \& Health Education,

University of Michigan School of Public Health,

1415 Washington Heights, SPH I Building, Room 3867,

Ann Arbor, MI 48109, USA

e-mail: alangfor@umich.edu
}

Keywords Direct-to-consumer genetic tests . Genetic testing $\cdot$ Health disparities · Numeracy . African American · Hispanic

\section{Introduction}

The number of genetic tests, including direct-to-consumer products, has grown tremendously in the past two decades, from approximately 100 in the early 1990 's to more than 1,000 in 2011 (Genetics and Public Policy Center 2006; McBride et al. 2010). Direct-to-consumer (DTC) genetic tests are those marketed directly to consumers via television, print advertisements, or the Internet. They allow a person to obtain genetic information without involving a doctor or insurance company in the process and provide an estimate of an individual's statistical risk for developing a specific health condition (Genetics Home Reference 2011). Major categories of DTC genetic tests include: 1) health-related tests to determine risk for developing specific diseases, 2) nutrigenomic tests to develop individualized diet plans, and 3) non-medical tests that scan the genome for variants related to different aspects of life such as ancestry or personality (National Human Genome Research Institute 2010b). There is ongoing debate about the widespread availability and appropriate regulation of DTC genetic tests (Kutz 2010; Hogarth et al. 2008). Currently, the Food and Drug Administration has oversight of DTC genetic tests and products, while the Federal Trade Commission regulates advertising (National Human Genome Research Institute 2010a).

In 2002, Myriad Genetics launched the first major DTC publicity campaign for its BRCA1/BRCA2 tests for risk of hereditary breast and ovarian cancer syndromes (McBride et al. 2010). Five years later, companies including 23 and Me, 
deCODE Genetics, Navigenics, and Knome started offering DTC genetic tests for various health conditions, as well as complete genome sequencing (McBride et al. 2010). Supporters of DTC genetic tests advocate that consumers have a right to obtain their genetic information without approval or interference from physicians or insurance companies (Hogarth et al. 2008; 23andMe 2011). Those against these tests argue that they can be misleading, poorly regulated, and lacking sufficient involvement of genetics service providers (Gollust et al. 2002; Matloff and Caplan 2008; McGuire and Burke 2008; Kutz 2010). A growing number of professional groups have issued position statements and guidelines about DTC genetic tests (American College of Medical Genetics 2008; American Society of Human Genetics 2007; National Society of Genetic Counselors 2007; Ameer and Krivoy 2009). For example, the American College of Medical Genetics suggests the following requirements for all DTC genetic testing protocols: 1) a knowledgeable professional be involved in the ordering and interpretation of DTC genetic tests; 2) consumers understand the limitations of what such tests can or cannot say about health; 3) scientific evidence about the test is clearly stated; 4) the clinical testing laboratory is accredited by a reputable organization; and 5) individual privacy concerns be addressed (American College of Medical Genetics 2008).

Previous studies have evaluated racial and ethnic differences in attitudes, knowledge, and preferences for both DTC and clinical genetic tests, yet the results have been mixed (Laskey et al. 2003; Hipps et al. 2003; Suther and Kiros 2009). Goddard et el evaluated public awareness and use of DTC nutrigenomic tests using the Behavioral Risk Factor Surveillance System (BRFSS) and found that race/ethnicity was not associated with awareness (Goddard et al. 2009). Regarding clinical genetic tests, Armstrong et al found that African American women with a history of breast or ovarian cancers were less likely than white women to seek out BRCA1/BRCA2 testing and counseling within an insured population (Armstrong et al. 2005). Singer et al also assessed preferences for clinical prenatal testing among African American, Latino, and White respondents using hypothetical scenarios with wording variations for males and females. They found that Latinos and African Americans were more likely than whites respondents to prefer clinical prenatal and adult genetic tests (Singer et al. 2004).

While the literature on numeracy and health is growing (Powers et al. 2010; Peters et al. 2007), there is a paucity of data on racial/ethnic disparities in numeracy. Disparities in numeracy have been shown among emergency department patients, diabetics, and people living with HIV (WaldropValverde et al. 2010; Osborn et al. 2009; Ginde et al. 2008). In cross-sectional surveys conducted with patients in emergency departments, Ginde et al found that, compared to white, Hispanic and black race were associated with lower numeracy after controlling for other demographic variables (Ginde et al. 2008). In another cross-sectional study of adult patients with type 2 diabetes, Osborn et al showed that African American race was associated with lower diabetes related numeracy (Osborn et al. 2009). Finally, in a sample of HIV positive African American, Hispanic, and white patients, Waldrop-Valverde et al found that medication management among African Americans was mediated by low numeracy (Waldrop-Valverde et al. 2010).

To date, few studies have evaluated the relationship between numeracy and genetic tests (DTC and clinical included). Genetic tests estimate an individual's statistical risk for developing a health condition. Since test results can be reported in a variety of ways including relative risk ratios, rates, and probabilities, some quantitative ability and comfort with numbers is needed (Leighton et al. 2011). Specifically, a person must have the ability to comprehend, use, and assign meaning to numbers (Reyna et al. 2009). This concept is broadly defined as numeracy. However, it should be noted that there are several definitions of numeracy in the literature.

A recent study by Leighton et al evaluated the public's understanding and ability to interpret DTC genetic test results compared to genetic counselors (2011). Both groups were provided with hypothetical sample test results explaining the risk of developing a health condition. Though numeracy was not measured directly in the study, the authors found that the public was significantly more likely than genetic counselors to misinterpret the meaning of results and to overestimate the usefulness of results for future medical care.

The objectives of our study are to examine the association of race/ethnicity on DTC genetic tests awareness and to evaluate the role that numeracy may play in this relationship within the 2007 Health Information National Trends Survey (HINTS). In this study, we explore how race/ethnicity and numeracy may interact to create a person's tendency to avoid or seek out DTC genetic tests, as well as their confidence and ability to use results to make health decisions. A better understanding of the relationships between these variables may inform how personal genomic service providers and healthcare professionals should communicate the benefits, limitations, and meaning of such tests.

\section{Methods}

\section{HINTS Public Use Data Set}

The Health Information National Trends Survey (HINTS) is a biennial, cross-sectional survey of American adults funded by the National Cancer Institute. HINTS collects nationally representative data about the public's use of general health 
and more specifically, cancer-related information. It assesses how people access and use health information, how people use information technology to manage their health and health information, and how people report engaging in healthy behaviors. The survey was conducted in 2003, 2005, and 2007. Our analyses use 2007 data, the first year DTC genetic tests awareness was assessed (National Cancer Institute 2009b).

\section{Participants}

A total of 7,674 individuals participated in the 2007 HINTS. For our analyses, we limited the sample to the 6,754 individuals who self-identified as being non-Hispanic Black/ African American, non-Hispanic White, or Hispanic/Latino. Due to small sample sizes, those who self-identified as Asian, American Indian or Alaskan Native, Native Hawaiian or Pacific Islander, or multiracial were excluded. Our subsample of non-Hispanic Black/African American, non-Hispanic White or Hispanic/Latino comprised 94\% of the full data set.

\section{Procedures}

The sample design for HINTS 2007 consisted of two samples with each sample selected from a separate frame. One sample was drawn as a Random Digit Dial telephone survey, using a Computer Assisted Telephone Interview (CATI) format. Survey administration averaged 30 minutes per respondent. The second national random sample was selected from a list of addresses from the United States Postal Service administrative records. All adults at each sampled address are asked to fill out the questionnaire and return it in a postage-paid envelope (National Cancer Institute 2009b). Approximately 3,582 surveys were completed by mail and 4,092 were completed via telephone (National Cancer Institute 2009b). Additional details about the study procedures and measures can be found elsewhere (National Cancer Institute 2009a).

\section{Measures}

DTC genetic tests awareness was the dependent variable. Participants were asked, "Genetic tests that analyze your $D N A$, diet, and lifestyle for potential health risks are currently being marketed by companies directly to consumers.

Have you heard or read about these genetic tests?" Response options were yes and no. Sociodemographic variables included in the analyses were race/ethnicity, gender, age, education, and income.

Respondents were asked to rate numeracy variables using a Likert-type scale with various response options. The first question was, "In general, how easy or hard do you find it to understand medical statistics?" Response options included very easy, easy, hard, or very hard. The second question was, "In general, I depend on numbers and statistics to help me make decisions about my health." Response options were strongly agree, agree, disagree, or strongly disagree. The third question was, "People can talk about the chance of something happening using either words, like "it rarely happens" or numbers, like "there's a 5\% chance." When people tell you the chance of something happening do you prefer they use words or numbers? Response options were generally prefer words, generally prefer numbers, or no preference. These three numeracy questions were asked in both the mail and telephone survey, and thus included in the analysis.

Numeracy variables were treated separately because they measure different aspects of numeracy. For example, the question about understanding medical statistics being easy or hard can be considered a general measure of subjective ability (Woloshin et al. 2005). Dependence on numbers and medical statistics to make health decisions may reflect one's confidence in using numeracy information. Furthermore, the tendency to favor numbers or words when discussing "the chance of something happening" reflects one's subjective numeracy preference (Fagerlin et al. 2007): that is, preference for numbers as opposed to facility with them. Pearson correlations for the three numeracy variables were evaluated and did not exceed 0.22 .

\section{Data Analysis}

Two logistic regression models were used in this study. The initial model examined the relationship between race/ethnicity (categorized as white, black, and Hispanic) and DTC genetic tests awareness controlling for sociodemographic variables. The second model added numeracy variables to assess how much, if at all, numeracy mediated the racial/ ethnic disparities in DTC genetic tests awareness. A chi square test was used to compare sociodemographic, DTC genetic tests awareness, and numeracy characteristics across racial/ethnic groups in Table 1. All analyses were conducted using PASW Statistics 18.0 (formerly known as SPSS).

\section{Results}

All sociodemographic variables (age, gender, education, and income) differed significantly across racial and ethnic categories (Table 1). Hispanic respondents were younger than white and black respondents. Compared to white and Hispanic respondents, a greater percent of black respondents were female. Black and Hispanic respondents had lower educational attainment and income than white respondents. In terms of difficulty in understanding medical statistics, 
Table 1 Sociodemographic, DTC genetic tests awareness, and numeracy characteristics by racial/ethnic group $(N=6,754)$

\begin{tabular}{|c|c|c|c|}
\hline & White & Black & Hispanic \\
\hline Age range $(\%)^{*}$ & $(n=5,445)$ & $(n=687)$ & $(n=622)$ \\
\hline $18-34$ & 11.9 & 18 & 30.2 \\
\hline $35-49$ & 22.7 & 25.8 & 30.3 \\
\hline $50-64$ & 33.2 & 36.8 & 24.7 \\
\hline $65-74$ & 16.8 & 12.5 & 10.8 \\
\hline $75+$ & 15.4 & 6.9 & 4 \\
\hline Gender $(\% \text { female })^{*}$ & 60.6 & 68.4 & 60.3 \\
\hline \multicolumn{4}{|l|}{ Education $(\%)^{*}$} \\
\hline$<$ High School & 6.2 & 15.6 & 27.9 \\
\hline High School & 24.5 & 26.7 & 27.2 \\
\hline Some College & 29.9 & 32.9 & 26.3 \\
\hline College & 39.4 & 24.8 & 18.6 \\
\hline \multicolumn{4}{|l|}{ Income range $(\%)^{*}$} \\
\hline$<\$ 19,999$ & 13.6 & 35.5 & 29.9 \\
\hline$\$ 20,000-34,999$ & 15.9 & 20.1 & 22.4 \\
\hline$\$ 35,000-49,999$ & 14.1 & 14.4 & 12.7 \\
\hline$\$ 50,000-74,999$ & 20.2 & 13.6 & 14.4 \\
\hline$\$ 75,000+$ & 36.3 & 16.4 & 20.6 \\
\hline \multicolumn{4}{|c|}{$\begin{array}{l}\text { In general, how easy or hard do you find it to understand medical } \\
\text { statistics }(\%)^{*}\end{array}$} \\
\hline Very easy & 13.4 & 12.4 & 9.6 \\
\hline Easy & 50.4 & 49.9 & 44.1 \\
\hline Hard & 30.7 & 29.6 & 35.3 \\
\hline Very hard & 5.6 & 8.1 & 11 \\
\hline
\end{tabular}

In general, I depend on numbers and statistics to help me make decisions about my health (\%)*

\begin{tabular}{|c|c|c|c|}
\hline Strongly agree & 9.7 & 13.5 & 13.9 \\
\hline Somewhat agree & 50 & 38.7 & 43.7 \\
\hline Somewhat disagree & 26.4 & 24.5 & 23.8 \\
\hline Strongly disagree & 13.9 & 23.3 & 18.6 \\
\hline \multicolumn{4}{|c|}{$\begin{array}{l}\text { When people tell you the chance of something happening, do you } \\
\text { prefer they use words or numbers }(\%)^{*}\end{array}$} \\
\hline Generally prefer numbers & 49.9 & 29.6 & 32.7 \\
\hline Generally prefer words & 30 & 46.6 & 47.2 \\
\hline No preference & 20.1 & 23.8 & 20.1 \\
\hline $\begin{array}{l}\text { Have you heard or read about } \\
\text { genetic tests (\%yes)* }\end{array}$ & 35.1 & 26.8 & 29.7 \\
\hline
\end{tabular}

*Statistically significant, $p<.05$

white respondents reported the highest degree of ease, while Hispanic respondents reported the greatest difficulty. With regard to depending on numbers and statistics to make health decisions, black and Hispanics respondents had similar rates and reported "strongly agree" more often than white respondents. In situations where the "chance of something happening" needed to be explained, white respondents were more likely to prefer numbers whereas black and Hispanic respondents reported a greater preference for words. Rates of DTC genetic tests awareness were significantly lower among black (23.8\%) and Hispanic (29.7\%) respondents, than white respondents (35.1\%).

Two different logistic regression models with multiple independent variables were run using DTC genetic tests awareness as the dependent variable. The first model included all sociodemographic variables including race/ethnicity, age, gender, education, and income as independent variables. As shown in Table 2, race/ethnicity was significantly associated with DTC genetic tests awareness. Compared to white respondents, black respondents $(\mathrm{OR}=0.79$; CI: 0.65 $0.97)$ were significantly less likely to have heard of DTC genetic tests. In contrast, Hispanic respondents $(\mathrm{OR}=1.05$; CI .85-1.29) did not significantly differ from white respondents in awareness of DTC genetic tests.

Awareness of DTC genetic tests increased across strata of income and education. However, only those in the highest category of income ( $\$ 75 \mathrm{~K}$ or more) compared to those making less than $\$ 19,999$ were significantly more likely to have heard of DTC genetic tests $(\mathrm{OR}=1.39$; CI: 1.14-1.69). Additionally, those with the highest level of education (college) compared to respondents with less than a high school education had significantly greater knowledge of DTC genetic tests $(\mathrm{OR}=2.43$; CI: 1.89-3.12). Compared to $18-$

Table 2 DTC genetic tests awareness by sociodemographic correlates. $(N=5,770)$

\begin{tabular}{|c|c|c|}
\hline & Odds ratio & $\mathrm{CI}$ \\
\hline \multicolumn{3}{|l|}{ Race/ethnicity } \\
\hline White (reference) & 1 & \\
\hline Black* & 0.79 & $0.65-0.97$ \\
\hline Hispanic & 1.05 & $0.85-1.29$ \\
\hline \multicolumn{3}{|l|}{ Income range $(\%)$} \\
\hline$<\$ 19,999$ (reference) & 1 & \\
\hline$\$ 20,000-34,999$ & 0.94 & $0.77-1.16$ \\
\hline$\$ 35,000-49,999$ & 1.02 & $0.82-1.26$ \\
\hline$\$ 50,000-74,999$ & 0.94 & $0.76-1.16$ \\
\hline$\$ 75,000+*$ & 1.39 & $1.14-1.69$ \\
\hline Gender (female) & 0.99 & $0.88-1.12$ \\
\hline \multicolumn{3}{|l|}{ Education (\%) } \\
\hline$<$ High School & 1 & \\
\hline High School & 0.95 & $0.73-1.22$ \\
\hline Some College* & 1.35 & $1.05-1.73$ \\
\hline College* & 2.43 & $1.89-3.12$ \\
\hline \multicolumn{3}{|l|}{ Age range $(\%)^{*}$} \\
\hline 18-34 (reference) & 1 & \\
\hline $35-49 *$ & 1.37 & $1.13-1.66$ \\
\hline $50-64 *$ & 1.75 & $1.46-2.1$ \\
\hline $65-74 *$ & 1.73 & $1.39-2.14$ \\
\hline $75+*$ & 1.28 & $1.01-1.62$ \\
\hline
\end{tabular}

*Statistically significant, $p<.05$ 
34 year olds, those aged 50-64 (OR=1.75, CI: 1.46-2.11) had the highest odds of DTC genetic tests awareness. Lastly, there was no difference in awareness of DTC genetic tests by gender $(\mathrm{OR}=0.99$; $\mathrm{CI}: 0.88-1.12)$.

In our second analysis (Table 3), two of the three numeracy variables were added to the model. Dependence on numbers and statistics to help make decisions about one's health, and preference for words or numbers when discussing "the chance of something happening" were kept as potential mediators, as they both had a relationship to black race and DTC genetic tests awareness in Table 1. Odds ratios for income, education, and age followed the same trend as noted above and remained significant, however

Table 3 DTC genetic tests awareness by sociodemographic and numeracy correlates. $(N=5,678)$

\begin{tabular}{|c|c|c|}
\hline & Odds ratio & CI \\
\hline \multicolumn{3}{|l|}{ Race/ethnicity } \\
\hline White (reference) & 1 & \\
\hline Black & 0.84 & $0.69-1.04$ \\
\hline Hispanic & 1.05 & $0.85-1.3$ \\
\hline \multicolumn{3}{|l|}{ Income range $(\%)$} \\
\hline$<\$ 19,999$ (reference) & 1 & \\
\hline$\$ 20,000-34,999$ & 0.94 & $0.77-1.17$ \\
\hline$\$ 35,000-49,999$ & 1.0 & $0.80-1.23$ \\
\hline$\$ 50,000-74,999$ & 0.92 & $0.75-1.14$ \\
\hline$\$ 75,000+*$ & 1.33 & $1.1-1.63$ \\
\hline Gender (female) & 1.03 & $0.92-1.17$ \\
\hline \multicolumn{3}{|l|}{ Education } \\
\hline$<$ High School & 1 & \\
\hline High School & 0.95 & $0.74-1.24$ \\
\hline Some College & 1.33 & $1.03-1.72$ \\
\hline College* & 2.29 & $1.76-2.96$ \\
\hline \multicolumn{3}{|l|}{ Age range } \\
\hline 18-34 (reference) & 1 & \\
\hline $35-49 *$ & 1.37 & $1.13-1.67$ \\
\hline $50-64 *$ & 1.75 & $1.46-2.11$ \\
\hline $65-74 *$ & 1.78 & $1.43-2.22$ \\
\hline $75+*$ & 1.35 & $1.06-1.73$ \\
\hline
\end{tabular}

In general, I depend on numbers and statistics to help me make decisions about my health.

Strongly agree (reference)

Somewhat disagree* $\quad 0.72 \quad 0.59-0.89$

Strongly disagree* $\quad 0.70 \quad 0.55-0.88$

When people tell you the chance of something happening, do you prefer they use words or numbers?

Generally prefer numbers (reference) 1

Generally prefer words* $\quad 0.8$

$0.69-0.92$

No preference

0.93

$0.8-1.08$

*Statistically Significant, $p<.05$ the effect of black race $(\mathrm{OR}=0.84$; CI: $0.69-1.04)$ was no longer significant. Gender remained non-significant in the full model. Both numeracy variables, however, were significant predictors of DTC genetic tests awareness. Compared to those who answered "strongly agree," respondents who strongly disagreed that numbers and statistics helped them make health decisions had lower odds of DTC genetic tests awareness $(\mathrm{OR}=0.7$; CI: $0.55-0.88)$. Compared to those who preferred numbers, respondents who preferred words when discussing "the chance of something happening" had significantly lower levels of DTC genetic tests awareness $(\mathrm{OR}=0.80$; CI: 0.69-0.92). We examined the interaction of race/ethnicity with the SES and numeracy variables in Tables 2 and 3, and found that none of these variables moderated the association of race/ethnicity on DTC genetic tests awareness.

\section{Discussion}

Our initial finding was that black respondents to the HINTS survey were significantly less likely than white respondents to have heard of DTC genetic tests, after controlling for sociodemographics including age, gender, income and education. This result is consistent with similar studies on genetic testing and related behaviors (Armstrong et al. 2005; Langford et al. 2010; Suther and Kiros 2009). Our second finding was that the association between black race and awareness of DTC genetic tests weakened from significant to non-significant once numeracy variables were added to the base model. While the difference in odds ratios between the two models is small, this change suggests that numeracy partially mediates this relationship. The finding also suggests that the racial and ethnic disparities in DTC genetic tests awareness are not attributed to socioeconomic status alone, but rather to one's preference for, and confidence level with regard to numeracy.

People who strongly disagreed that they depend on numbers and statistics to help them make health decisions were the least likely to have heard of DTC genetic tests. This group may be less likely to proactively seek out information about DTC genetic tests due to limited confidence in their ability to interpret their meaning. As such, they may not explore medical websites or other outlets such as health magazines where DTC or other clinical genetic tests may be advertised. This differential exposure to health information may contribute to more disparities in knowledge and access to information about DTC and clinical genetic tests.

Our study also suggests the need for further research on the impact of numeracy on DTC genetic test awareness, utilization, and medical decision making based on results. The format in which numbers and risk information is presented to consumers warrants more attention. Although 
many studies have examined the link between numeracy and various types of risk communication, there is no consensus in the field on the "best" way to present health information. For example, probabilities, risk comparisons, graphical displays, ratios, and qualitative explanations have all been used to present risk information (Akl et al. 2011; Lipkus 2007; Fischhoff et al. 2011; Leighton et al. 2011). Given that numeracy levels in the U.S. are generally low and that great variation exists among consumers with regard to preferences for risk information (Reyna et al. 2009), a variety of tools are needed to ensure that people can use numbers in a way that facilitates informed medical decisions. One emerging strategy is to tailor format and content to individual needs and preferences (Kreuter et al. 1999). Additionally, simple to administer numeracy scales already exist and can potentially be used to facilitate tailoring on numeracy (Fagerlin et al. 2007).

\section{Practice Implications}

Based on our findings, we propose that numeracy may be a barrier to access and knowledge of useful genetic information among black consumers. More research, including both qualitative and quantitative, is needed to understand how black consumers perceive, access, and utilize DTC genetic tests. This holds true for Hispanic consumers as well. Increased community engagement may inform which strategies are most helpful to diverse populations for evaluating the benefits and drawbacks of DTC genetic tests. For example, online education modules, webinars, community forums, advocacy groups, newsletters, and social media are being used by the GenoCommunity Think Tank, the Genetic Alliance, and other groups to educate the public about genomics (GenoCommunity Think Tank 2011; Genetic Alliance 2011).

Although Hispanic respondents in our study did not differ significantly from white respondents in DTC genetic tests awareness, little is known about Hispanic consumers with regard to genetic tests. A study done with a Puerto Rican sample found that the majority of respondents $(56 \%)$ were aware of DTC genetic tests (Ortiz et al. 2011). In contrast, another study found that Hispanics had low awareness of clinical genetic tests for breast cancer, despite reporting a desire to receive more information about hereditary cancer and genetic testing (Ramirez et al. 2006). A better understanding of how, if at all, DTC genetic companies advertise to Hispanic audiences warrants more attention, especially pertaining to availability of Spanish language and other culturally appropriate materials.

Given the growing number of users of DTC genetic tests, genetic counselors and primary care physicians may see increases in questions and concerns from patients. To accommodate the diversity in numeracy skill, preference, and comfort among consumers, these clinicians may benefit from training on how to tailor communications of risk information. Screening tools that assess patient preferences for health information may also be helpful (e.g. numbers, words, or graphs), although it is not clear that patients know what formats they actually understand best.

Finally, alternative ways of conveying numbers warrants more attention. For example, pictographs, used to make risk-related statistics easier to interpret, and social math involving relation of information to things people already understand (e.g. number of people who can fit into a 747 airplane or school bus) may be useful tools for explaining risk information to low numerate consumers (CDC 2008; Garcia-Retamero and Galesic 2010; Zikmund-Fisher et al. 2010; Center for Health Improvement 2004). It may also be useful to assess the effectiveness of combining numerical data with qualitative explanations when reporting results of DTC and clinical genetic tests.

\section{Study Limitations}

Limitations include our inability to explore the full domain of numeracy, as two of the five items in HINTS 2007 were excluded because they were only asked in one format of the survey (phone or mail). Measuring race is complex (Kaplan and Bennett 2003). Since broad racial and ethnic categories were used and no multiracial classification was evaluated, we cannot account for within group differences among white, black, and Hispanic respondents. This limits the precision and generalizability of our inferences. It should also be noted that achieving statistical significance in a large sample does not necessarily imply clinical significance. Finally, trends in DTC genetic tests awareness and numeracy over time could not be evaluated as these questions were asked in the HINTS 2007 survey, prior to mainstream media coverage of genetic testing that has occurred in recent years. For example, in 2008, the Genetic Information Nondiscrimination Act was passed (110th Congress 2008) and Time magazine named "The Retail DNA Test" its Invention of the Year (Hamilton 2008).

\section{Conclusion}

To our knowledge, this is the first study to directly examine the role of numeracy on DTC genetics test awareness. Our findings show that among black, white, and Hispanic respondents to the HINTS 2007 survey, racial and ethnic disparities exist with regard to DTC genetic tests awareness. However, these disparities are no longer significant once accounting for respondents' numeracy, suggesting that numeracy may partially explain an individual's willingness to seek out and pay attention to DTC genetic tests. Given the 
implications for health decisions based on DTC genetic test results, more research is needed to better understand the relationship between numeracy and DTC genetic testing.

\section{References}

110th Congress (2008). H.R.493. http://thomas.loc.gov/cgi-bin/ bdquery/z?d110:h.r.00493. Accessed 5 June 2011.

23andMe (2011). Core values. https://www.23andme.com/about/values/. Accessed 18 Sept 2011.

Akl, E. A., Oxman, A. D., Herrin, J., Vist, G. E., Terrenato, I., Sperati, F., et al. (2011). Using alternative statistical formats for presenting risks and risk reductions. Cochrane Database of Systematic Review (3), CD006776. doi:10.1002/14651858.CD006776.pub2.

Ameer, B., \& Krivoy, N. (2009). Direct-to-consumer/patient advertising of genetic testing: A position statement of the American College of Clinical Pharmacology. Journal of Clinical Pharmacology, 49(8), 886-888. doi:10.1177/0091270009335948.

American College of Medical Genetics (2008). ACMG statement on direct-to-consumer genetic testing. http://www.acmg.net/AM/ Template.cfm?Section=Policy_Statements\&Template $=/ \mathrm{CM} /$ ContentDisplay.cfm\&ContentID=2975. Accessed 18 Sept 2011.

American Society of Human Genetics (2007). ASHG statement on direct-to-consumer genetic testing in the United States. http:// ashg.org/pdf/dtc statement.pdf. Accessed Sept 2011.

Armstrong, K., Micco, E., Carney, A., Stopfer, J., \& Putt, M. (2005). Racial differences in the use of BRCA1/2 testing among women with a family history of breast or ovarian cancer. Journal of the American Medical Association, 293(14), 1729-1736. doi:10.1001/ jama.293.14.1729.

CDC (2008). Adding power to our voices: A framing guide for communicating about injury. http://wwwn.cdc.gov/NCIPC-SuccessStory/ files/Adding $\% 20$ Power $\% 20$ to $\% 20$ Our $\% 20$ Voices $\% 20$ Injury $\%$ 20Framing\%20Guide.pdf. Accessed 22 Sept 2011.

Center for Health Improvement (2004). Using data strategically: Social math. http://www.chipolicy.org/pdf/TA5.pdf. Accessed 23 Sept 2011.

Fagerlin, A., Zikmund-Fisher, B. J., Ubel, P. A., Jankovic, A., Derry, H. A., \& Smith, D. M. (2007). Measuring numeracy without a math test: Development of the subjective numeracy scale. Medical Decision Making, 27(5), 672-680. doi:10.1177/ 0272989x07304449.

Fischhoff, B., Brewer, N., \& Downs, J. (2011). Communicating risks and benefits: An evidence-based user's guide http:// www.fda.gov/downloads/AboutFDA/ReportsManualsForms/ Reports/UCM268069.pdf. Accessed 22 Sept 2011.

Garcia-Retamero, R., \& Galesic, M. (2010). Who profits from visual aids: Overcoming challenges in people's understanding of risks [corrected]. Social Science \& Medicine, 70(7), 1019-1025. doi:10.1016/j.socscimed.2009.11.031.

Genetic Alliance (2011). Genetic alliance resources and services. http://www.geneticalliance.org/resources\#engage. Accessed 20 Sept 2011.

Genetics Home Reference (2011). What is direct-to-consumer genetic testing? http://ghr.nlm.nih.gov/handbook/testing/directtoconsumer. Accessed 5 Feb 2011.

GenoCommunity Think Tank (2011). Knowledge modules. http://geno community.org/index.php?note=Events. Accessed 5 June 2011.

Ginde, A. A., Clark, S., Goldstein, J. N., \& Camargo, C. A., Jr. (2008). Demographic disparities in numeracy among emergency department patients: Evidence from two multicenter studies. Patient Education and Counseling, 72(2), 350-356. doi:10.1016/j. pec.2008.03.012.
Goddard, K. A., Duquette, D., Zlot, A., Johnson, J., Annis-Emeott, A., Lee, P. W., et al. (2009). Public awareness and use of direct-toconsumer genetic tests: Results from 3 state population-based surveys, 2006. American Journal of Public Health, 99(3), 442445. doi:10.2105/AJPH.2007.131631.

Gollust, S. E., Hull, S. C., \& Wilfond, B. S. (2002). Limitations of direct-to-consumer advertising for clinical genetic testing. Journal of the American Medical Association, 288(14), $1762-1767$.

Hamilton, A. (2008). Best inventions of 2008. http://www.time.com/ time/specials/packages/article/0,28804,1852747_1854493,00. html. Accessed 5 June 2011.

Hipps, Y. G., Roberts, J. S., Farrer, L. A., \& Green, R. C. (2003). Differences between African Americans and Whites in their attitudes toward genetic testing for Alzheimer's disease. Genetic Testing, 7(1), 39-44. doi:10.1089/109065703321560921.

Hogarth, S., Javitt, G., \& Melzer, D. (2008). The current landscape for direct-to-consumer genetic testing: Legal, ethical, and policy issues. Annual Review of Genomics and Human Genetics, 9, 161-182. doi:10.1146/annurev.genom.9.081307.164319.

Kaplan, J. B., \& Bennett, T. (2003). Use of race and ethnicity in biomedical publication. JAMA: The Journal of the American Medical Association, 289(20), 2709-2716. doi:10.1001/jama. 289.20.2709.

Kreuter, M. W., Strecher, V. J., \& Glassman, B. (1999). One size does not fit all: The case for tailoring print materials. Annals of Behavioral Medicine, 21(4), 276-283.

Kutz, G. (2010). Direct-to-consumer genetic tests: Misleading test results are further complicated by deceptive marketing and other questionable practices (p. 33). Washington: U.S. Government Accountability Office.

Langford, A., Resnicow, K., \& An, L. (2010). Clinical trial awareness among racial/ethnic minorities in HINTS 2007: Sociodemographic, attitudinal, and knowledge correlates. Journal of Health Communication, 15(Suppl 3), 92-101. doi:10.1080/10810730. 2010.525296.

Laskey, S. L., Williams, J., Pierre-Louis, J., O'Riordan, M., Matthews, A., \& Robin, N. H. (2003). Attitudes of African American premedical students toward genetic testing and screening. Genetics in Medicine, 5(1), 49-54. doi:10.1097/01.GIM. 0000046360.61376.EB.

Leighton, J. W., Valverde, K., \& Bernhardt, B. A. (2011). The general public's understanding and perception of direct-toconsumer genetic test results. Public Health Genomics. doi:10.1159/000327159.

Lipkus, I. M. (2007). Numeric, verbal, and visual formats of conveying health risks: Suggested best practices and future recommendations. Medical Decision Making, 27(5), 696-713. doi:10.1177/ 0272989x07307271.

Matloff, E., \& Caplan, A. (2008). Direct to confusion: Lessons learned from marketing BRCA testing. The American Journal of Bioethics, 8(6), 5-8. doi:10.1080/15265160802248179.

McBride, C. M., Wade, C. H., \& Kaphingst, K. A. (2010). Consumers' views of direct-to-consumer genetic information. Annual Review of Genomics and Human Genetics, 11, 427-446. doi:10.1146/ annurev-genom-082509-141604.

McGuire, A. L., \& Burke, W. (2008). An unwelcome side effect of direct-to-consumer personal genome testing: Raiding the medical commons. Journal of the American Medical Association, 300(22), 2669-2671. doi:10.1001/jama.2008.803.

National Cancer Institute (2009a). Health Information National Trends Survey (HINTS) 2007: Final report. http://hints.cancer.gov/docs/ HINTS2007FinalReport.pdf. Accessed 7 May 2011.

National Cancer Institute (2009b). HINTS survey instruments. http://hints.cancer.gov/instrument.aspx. Accessed 7 May 2011. 
National Human Genome Research Institute (2010a). Direct to consumer marketing of genetic tests. http://www.genome.gov/ 12010659. Accessed 5 Feb 2011.

National Human Genome Research Institute (2010b). Frequently asked questions about genetic testing. http://www.genome.gov/ 19516567\#al-5. Accessed 7 Feb 2011.

National Society of Genetic Counselors (2007). Position statements: Direct to consumer genetic testing. http://www.nsgc.org/Media/PositionStatements/tabid/330/Default.aspx\#DTC. Accessed 18 Sept 2011.

Ortiz, A. P., Lopez, M., Flores, L. T., Soto-Salgado, M., Finney Rutten, L. J., Serrano-Rodriguez, R. A., et al. (2011). Awareness of directto-consumer genetic tests and use of genetic tests among Puerto Rican adults, 2009. Preventing Chronic Disease, 8(5), A110.

Osborn, C. Y., Cavanaugh, K., Wallston, K. A., White, R. O., \& Rothman, R. L. (2009). Diabetes numeracy: An overlooked factor in understanding racial disparities in glycemic control. Diabetes Care, 32(9), 1614-1619. doi:10.2337/dc09-0425.

Peters, E., Hibbard, J., Slovic, P., \& Dieckmann, N. (2007). Numeracy skill and the communication, comprehension, and use of riskbenefit information. Health Affairs (Millwood), 26(3), 741-748. doi:10.1377/hlthaff.26.3.741.

Powers, B. J., Trinh, J. V., \& Bosworth, H. B. (2010). Can this patient read and understand written health information? Journal of the American Medical Association, 304(1), 76-84. doi:10.1001/ jama.2010.896.

Genetics and Public Policy Center (2006). Public health at risk: Failures in oversight of genetic testing laboratories. http://www.dna
policy.org/images/reportpdfs/PublicHealthAtRiskFinalWith Cover.pdf. Accessed 5 May 2011.

Ramirez, A. G., Aparicio-Ting, F. E., de Majors, S. S., \& Miller, A. R. (2006). Interest, awareness, and perceptions of genetic testing among Hispanic family members of breast cancer survivors. Ethnicity \& Disease, 16(2), 398-403.

Reyna, V. F., Nelson, W. L., Han, P. K., \& Dieckmann, N. F. (2009). How numeracy influences risk comprehension and medical decision making. Psychological Bulletin, 135(6), 943-973. doi:10.1037/a0017327.

Singer, E., Antonucci, T., \& Van Hoewyk, J. (2004). Racial and ethnic variations in knowledge and attitudes about genetic testing. $\mathrm{Ge}$ netic Testing, 8(1), 31-43. doi:10.1089/109065704323016012.

Suther, S., \& Kiros, G. E. (2009). Barriers to the use of genetic testing: A study of racial and ethnic disparities. Genetics in Medicine, 11 (9), 655-662. doi:10.1097/GIM.0b013e3181ab22aa.

Waldrop-Valverde, D., Osborn, C. Y., Rodriguez, A., Rothman, R. L., Kumar, M., \& Jones, D. L. (2010). Numeracy skills explain racial differences in HIV medication management. AIDS and Behavior, 14(4), 799-806. doi:10.1007/s10461-009-9604-4.

Woloshin, S., Schwartz, L. M., \& Welch, H. G. (2005). Patients and medical statistics. Interest, confidence, and ability. Journal of General Internal Medicine, 20(11), 996-1000. doi:10.1111/ j.1525-1497.2005.00179.x.

Zikmund-Fisher, B. J., Fagerlin, A., \& Ubel, P. A. (2010). A demonstration of "less can be more" in risk graphics. Medical Decision Making, 30(6), 661-671. doi:10.1177/0272989x10364244. 